\title{
Research Review and Prospect on the Factors Affecting the Successful Brand Extension in Chinese Context
}

\author{
Zhiwei He \\ Chinese Graduate School, Panyapiwat Institute of Management, Thailand \\ Sichuan University JInjiang College, China \\ 15627657@qq.com
}

Key Word: Chinese context, brand extension, success Factors, overview and prospects

\begin{abstract}
As an important research field of brand equity theory, brand extension theory has been extensively studied by scholars all over the world, and has become an important strategic tool widely used by enterprises. Brand extension has been introduced into China since the mid-1990s. It has experienced a rapid development process from preliminary exploration to in-depth exploration and then to expanding research. Based on the classical A\&K theoretical model, this paper combs the literature of brand extension in China and foreign countries in the past 30 years from six aspects: parent brand factor, extension product factor, relationship factor between extension product and parent brand, consumer factor, marketing factor and social factor, and constructs a model for successful brand extension, and provides experience and basis for reference in theory and practice, and provides ideas for future research in this field in the context of China.
\end{abstract}

\section{Introduction}

In the 1980s, brand extension became a common strategy adopted by product managers in international enterprises (Tauber, 1988). That's mainly because brand extension can not only improve the success rate of new products (Aaker, 1991; Simon and Sullivan, 1993; Collins-Dodd and Louviere, 1999), but also can strengthen the parent brand in the mind of customers, promoting its popularity and reputation (Park, Jaworski and Mac Innis, 1986; Dacin and Smith, 1994; Lehu, 2004), and increasing its market share, etc. Data show that more than $80 \%$ of new products in the United States enter the market through brand extension. Some well-known enterprises in China, such as Haier, Gree, etc, have also adopted a large number of brand extension strategies and achieved success. Is the success of these brand extension strategies accidental or inevitable? What are the factors affecting the success of brand extension? What are the key and specific factors? Is there any interaction between the factors? These are the core issues that can not be avoided to guide the practice of brand extension.

\section{Basic Concept of Brand Extension}

With the application of brand extension strategies to practice, the theoretical research of brand extension has also attracted enormous attention. Scholars defined brand extension from the perspectives of the nature and the role of brand extension, which is shown in Table 1.

Table 1 Overview of Brand Extension Definitions

\begin{tabular}{|c|c|}
\hline Brand extension definitions & \\
\hline $\begin{array}{l}\text { Brand extension refers to the use of the leverage of a well known brand name } \\
\text { in one category to launch a new product in a different category }\end{array}$ & Tauber, 1981 \\
\hline $\begin{array}{l}\text { Brand extension is the use of a successful brand name to launch new or } \\
\text { modified products in a new category }\end{array}$ & Kotler, 1994 \\
\hline $\begin{array}{l}\text { Brand extension is the introduction of new products in the category of parent } \\
\text { brand to market or the introduction of new products in a new category to the } \\
\text { market. }\end{array}$ & Aaker \& Keller, 1990 \\
\hline Brand extension refers to the application of existing brand names to products & Sheinin \& Schmitt, 1994 \\
\hline
\end{tabular}


in related categories or new categories, which includes two types. One is that extension products have similar attributes with the existing products of the parent brand, which is called product category extension; the other is the extension of the concept of new competitive products from existing product categories, which is called new product concept extension.

Brand extension refers to the use of the original brand name for product line expansion or launching products in new category based on the established quality or reputation of the original brand.

Brand extension refers to the application of a famous brand or a finished product brand to products different from existing products or original products. Brand extension is used as a strategy for enterprises to launch new products and to expand markets. It is also an important way for enterprises to utilize their own brand assets.

Brand extension refers to the application of the original brand to new products or services on the basis of established brand reputation so as to reduce the risk of new products entering the market and to obtain greater market returns with less marketing costs.

Brand extension, also known as brand expansion, refers to the process in which an enterprise applies a well-known brand or a successful brand with market influence to a product completely different from the famous product or the original product, in order to launch a new product.

Sources: reviewed by the author

\section{Brand extension theories}

\subsection{Affect transfer model}

Scholars mainly use the affect transfer model to describe a consumer's evaluation of extension products, which is shown in Figure 1.

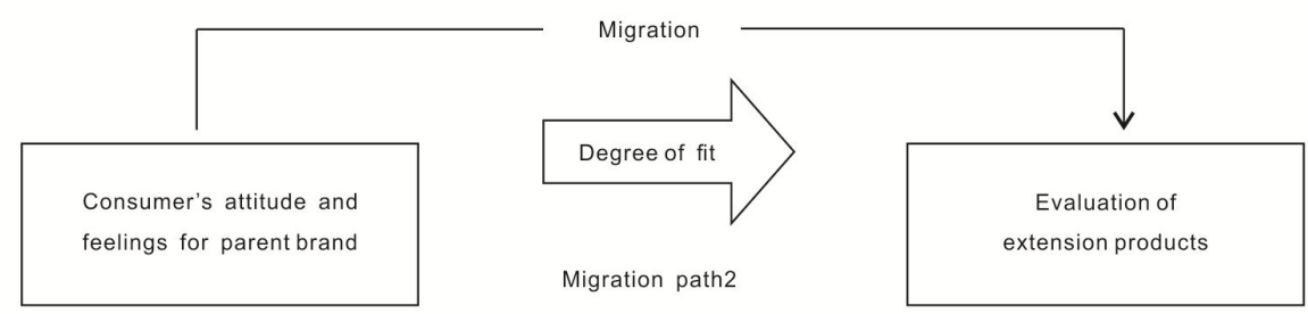

Fig.1. Affect transfer model

A consumer's attitude and preference towards parent brand can be transferred to extension products through two possible migration paths, which can have an impact on brand extension evaluation.

Migration path 1 describes a direct migration process. Boush et al. explained the migration with generalization and assimilation of stimuli. They believed that the attitude toward a brand is a conditioned reflex between the parent brand and its consumers. When the conditioned stimuli, namely the name of the parent brand, appears, it causes a consumer to experience certain emotions, such as affection. Migration path 2 describes an indirect migration process. The migration of a consumer's emotion toward parent brand to extension products depends on the degree of similarity between the two perceived by consumers. If the similarity between the extension products and the parent brand is high, the consumer's preference for the parent brand can migrate smoothly to the extension products, thus generating a positive evaluation extension products; when the similarity between the extension products and the parent brand product is low, the consumer's preference for the parent brand can not migrate smoothly to the extension products, which causes a negative 
evaluation of the extension products due to cognitive conflicts.

\subsection{Attribute demand-association model}

Proposed by Bhat and Reddy, the attribute demand-association model appeared later than the affect transfer model. The model considers that the main factor affecting a consumer's evaluation of extension products is not the consumer's attitude toward the parent brand or the similarity between the extension products and the parent brand products, but the degree to which the specific attribute associations of the parent brand is needed by the extension products, which can be expressed by AiIi. Ai represents the specific attribute association of the parent brand. Ii represents how much the specific attribute association of the parent brand is needed by the extension products. This model assumes that a consumer would first figure out whether the specific attribute association of parent brand (i.e. some attributes or benefits that distinguish a brand from a competing brand) can fulfill his demands for the attributes or benefits of its extension products before evaluating each extension products. When the specific attribute association of the parent brand is consistent with the consumer's demand for extension products, the consumer would have a higher evaluation of the extension products, and vice versa.

\subsection{Category theory and generalization theory}

Category theory is mainly used to explain a consumer's evaluation of brand extension. It holds that the key to a consumer's acceptance of brand extension lies in his perception that the extension products belongs to the same category as the parent brand. In this way, he can transfer the associations of the parent brand to the extension products. The judgment of whether the extension products and the parent brand belong to the same category mainly depends on the fit or similarity between the two perceived by consumers. Category theory holds that a consumer has a logical prediction of how the brand would extend based on his knowledge about the brand before the actual brand extension begins.

Generalization theory holds that in learning the response to a certain stimulus, the response can be evoked not only by the original stimuli, but also by similar stimuli. That is to say, the effect of the original stimuli can spread to other similar stimuli, which is called generalization. The degree of generalization is closely related to the similarity of the two stimuli. The more similar a new stimulus to the original conditioned one, the more significant the generalization is; on the contrary, the less similar the two stimuli are, the less significant the generalization is.

\section{Factors affecting brand extension}

\subsection{The parent brand}

Existing studies on brand extension have made in-depth discussion on the impact of parent brand-related factors. This study summarizes that parent brand-related factors mainly includes the following dimensions: perceived quality of parent brand, parent brand breath, the attribute associations of parent brand, the technical level of parent brand, the history of parent brand extension, etc.

\subsubsection{Perceived quality of parent brand}

Early studies by Boush et al. found that if there is a high fit between parent brand and its extension products, a consumer's attitude towards the parent brand would affect their attitude towards the brand extension. Suder and Brodie's research in New Zealand found that the perceived quality of parent brand products by a consumer has a significant direct impact on his evaluation of the brand extension and can exert indirect impact through its interaction with substitutability. Bottomley and Dolye's research in the UK found that after they eliminated the multicollinearity between the main effect and interaction effect by residual centering method, both the direct impact of the perceived quality of parent brand and the indirect impact of the interaction within the three fit dimensions of complementarity, substitutability and transferability are quite significant; besides, Compared with the main effect, the impact of interaction effect is much weaker. The research of Fu Guoqun in 
China also proved the impact of the perceived quality of parent brand products on its brand extension evaluation.

\subsubsection{Parent brand breadth}

Boush and Loken's research results showed that brand breadth directly impacts a consumer's evaluation of extension fit, and thus indirectly affects the consumer's brand extension evaluation. Experiments by Meyvis and Janiszewski proved this hypothesis that when a rand with great breadth has positive benefit-focused association in extension category, consumers tend to prefer the extension of the brand with wide breadth even if the extension category is more similar to that of a brand with narrow breadth.

\subsubsection{Attribute-based association of parent brand}

Dawar pointed out that when parent band have strong association with only one product, a consumer can have a stronger perception of the extension fit because he can more easily extract from his memory the knowledge about products with strong association with the parent brand.

\subsubsection{The history of parent brand extension}

In his research, Delvecchio argued that the past history of parent brand extension has a positive impact on parent brand strength. Swamin and Tayur's research results show that previous brand extension can impact a consumer's purchase behavior of newly launched extension products, and the impact is even more significant especially when the consumer has low loyalty to the parent brand or prefer the previously launched extension products.

\subsection{Extension products-related factors}

\subsubsection{The quality of extension products}

When there is a small perceived quality disparity between existing brands in a category, a consumer would infer the quality of extension products according to the quality level of the existing brands, while the influence of technology level of the parent brand would be weakened. On the contrary, when there is a remarkable quality disparity between existing brands in a category, the quality of the existing brands is no longer a criterion to evaluate the quality of extension products; instead, the consumer would evaluate the quality of extension products based on the technical level of the parent brand.

\subsubsection{The difficulty of manufacturing extension products}

The difficulty of manufacturing extension products also directly affects the success of brand extension. Higher difficulty in manufacturing extension products leads to a consumer's high brand extension evaluation, while the low technology of extension products would lead to a consumer's low brand extension evaluation (Aaker and Keller, 1990). Jun et al. proposed that consumers may use the technology level of existing parent brand products as a reference to evaluate its extension products, so when the parent brand extends to products requiring higher technology, consumers might question the company's capability of manufacturing the extension products if they use the low technology level of the parent brand as a criterion.

\subsection{The relationship between extension products and the parent brand}

The existing studies on brand extension summarize the relationship between extension products and the parent brands as follows: product fit, association fit and cultural fit.

\subsubsection{Product fit}

The research of scholars has proved that the perceived fit between the extension products and the parent brand would have an important impact on the feedback effect of brand extension. Boush and Loken divided brand extension into typical and a typical zones to test the impact of different ways on a consumer's brand extension evaluation. When the extension products have a high degree of fit with the original products of the parent brand, the brand extension is called typical brand extension; when the extension products have a low degree of fit with and the original products of the parent brand, the brand extension is called atypical brand extension.

\subsubsection{Association fit}

Based on Park and Lawson's research, Alba put forward the concept of brand-specific association fit, and tested its impact on a consumer's brand extension evaluation. They believe that a brand has 
some attribute or benefit associations that are not related to its products other than brand concept association. Their empirical research found that the extension of parent brand to products with no similar attributes but related brand-specific associations receive positive feedback than to products with similar attributes but unrelated brand-specific associations, which proves that in some cases brand-specific association fit has a greater impact on a consumer's brand extension evaluation than product attribute fit does.

4.3.3 Cultural fit

Zhou Luyang used China's time-honored brands as research objects to carry on brand extension researches. Considering the unique cultural attributes of a time-honored brands, she put forward the concept of cultural fit for the first time, arguing that cultural fit is a further refinement of the concept of brand concept consistency or brand association consistency; moreover, she also proved through empirical studies that there is the cultural fit factor affecting the extension of china's time-honored brands. The cultural fit in the extension of atime-honored brands refers to the fit or similarity or compatibility in historical inheritance and national characteristics between the parent brand and its extension products. It is confirmed by empirical research that cultural fit is one of the important factors affecting the success of a time-honored brand extension. The stronger the cultural fit between the extension products and the parent brand is, the more positive evaluation a consumer would have for the brand extension.

\subsection{Consumer-related factors}

\subsubsection{Connsumer innovativeness}

Dowling and Staelin's research found that different consumers have different perceptions of risks. In the process of brand extension evaluation, consumers with poor innovativeness would link high risk with low fit, thus showing resistance to brand extension. Based on the new-product diffusion theory, Klink and Smith proposed that consumers with different innovativeness level have different responses to brand extension. Consumers with higher innovativeness have higher tolerance of risk, which makes him easier to accept low-perceived fit brand extension. On the contrary, consumers with low innovativeness have low tolerance of risk, which makes him more difficult to accept low-perceived fit brand extension. Their empirical studies showed that a consumer's innovativeness level has a significant positive effect on brand extension evaluation and can regulate the relationship between the perceived fit and brand extension evaluation. With the increase of a consumer's innovativeness level, the impact of perceived fit on brand extension evaluation would decrease.

\subsubsection{Consumer involvement}

Barone further pointed out that consumers need more cognitive resources to evaluate the perceived fit between parent brand and its extension products. Therefore, only under the condition of high involvement can good mood stimulate a consumer to consider the perceived fit between parent brand and its extension products, thus indirectly affecting the consumer's brand extension evaluation. The results of Barone's research confirmed the above hypothesis, showing that under the condition of high involvement, mood can indirectly affect a consumer's evaluation of medium-level fit brand extension through the intermediary effect of perceived fit; on the contrary, under the condition of low involvement, mood, as an intuitive feeling, can directly impact a consumer's brand extension evaluation. Yuan Yongdan's research confirmed that involvement level can regulate the impact of perceived fit on brand extension evaluation. Under high involvement level, perceived fit has a more significant impact on brand extension evaluation; under low involvement level, perceived fit also has a significant but weaker impact on brand extension evaluation.

\subsubsection{Consumer's risk Perception}

Klink and Smith tested the impact of a consumer's new product adoption tendency on brand extension evaluation. They proposed that the perceived fit between parent brand and its extension products would affect a consumer's perception of the risk of brand extension. With the decrease of the fit, the consumer's perceived risk would increase while his evaluation of brand extension would decrease. However, for consumers with different new product adoption tendencies, the impact of perceived risk will be different. Early adopters, namely high-innovativeness consumers, are more 
willing to face risks and are more likely to accept low-fit extensions, while late adopters, namely low-innovativeness consumers, may have stronger resistance to low-fit extensions. In this sense, they expected that in brand extension evaluation, low-innovativeness consumers would be more influenced by perceived fit than high-innovativeness consumers.

\subsection{Marketing factors}

When the new products in brand extension are launched to market, they are influenced by various marketing activities such as advertisement and the promotion campaign of the company. Scholars have studied the role of various marketing factors in a consumer's brand extension evaluation, mainly including the three factors of marketing support, channel members' attitude, and competition patterns.

\subsubsection{Marketing support}

Bridges and others believed that the significance and relevance of the dominant association of parent brand in brand extension are the key factors affecting a consumer's perceived fit. When the correlation of the dominant association of parent brand with the brand extension is weak or its significance is not strong enough, consumers perceived fit would be weakened. Bridges et al. examined the role of relational communication strategy and descriptive communication strategy in improving a consumer's perception of brand extension fit and in enhancing brand extension evaluation, finding that both strategies significantly improved the consumer's perception of brand extension fit and their brand extension evaluation compared with the situation in which no external information is available, thus proving that marketing communication strategy has positive significance in improving a consumer's evaluation of low-fit brand extension.

\subsubsection{Attitude of channel members}

For products that need to be sold through retail channels, a retailer's attitude also affects the success rate of brand extension. The higher the retailer's acceptance of brand extensions, the higher the probability of successful brand extension is (Nijssen, 1999). The positive support of channel members can effectively promote the performance of extension products in the terminal sales, and thus have a positive impact on the success of extension (Yu Chunling, 2012).

\subsubsection{Competition patterns}

Considering the unstable competition in extension products market, even if there are leading brands in the market, brand extension can still succeed as long as the market is unstable and there are still blind spots in customer demand that can be developed (Yu Chunling, 2012).Yu Chunling's research divided instability in competition into two types: one is when the competitive pattern has not yet formed, the leading brand has not appeared yet or has limited influence, and the whole market competition is not fierce; the other is when with competitive pattern just formed and existence of some leading brands, there are still blind spots in consumer demand that have not been discovered. Therefore, the emergence of new brands or discovery of consumer demand can affect the competition pattern of the whole market.

\subsection{Social factors}

\subsubsection{Cultural difference}

Magna and John have proposed that due to lack of social relationships, individuals in Western societies believe that the world structure is discrete and discontinuous, and that the behavior of their objects can be predicted by rules and characteristics. On the contrary, individuals in Eastern cultures pay more attention to the relationship between their objects because they are in numerous social relationships. Consumers in western culture often evaluate brand extension fit based on the category and attribute similarity of products. When there is much category difference between extension products and parent brand, they tend to think that the extension fit is very poor. Consumers in East Asian culture pay more attention to the relationship between their objects, so they can identify other relationships between parent brand and extension products. For example, an East Asian consumer evaluates extension fit based on function complementarily, or evaluate the relationship between extension products and parent brand based on their overall reputation or his feeling for the parent brand. Therefore, compared with western consumers, east Asian consumers have higher perception 
and higher evaluation of brand extension.

\subsubsection{Policy direction}

In the Chinese context, the government's guiding policies play an important role in an industry's development, which is an affecting factor that does not exist or is not significant in the non-Chinese context. However, after review of the existing research literature, it is found that there is no theoretical research on this factor and only a few practical analysis of some actual enterprise cases.

\section{Theoretical Model of successful Brand Extension}

There are two kinds of methods in empirical studies: one is to investigate and study cases divergently without the guidance of theoretical framework, draw conclusions by summarizing the results of investigation, and then analyze the conclusions to form a theoretical framework; the other is to investigate and study sample cases according to the existing or newly established theoretical framework, and finally draw the corresponding conclusions through the verification and revision of the theoretical framework(Li Fei et al., 2009).This paper combines the two methods. For the factors affecting the success of brand extension, this paper chooses at least one variable which is supported by data from empirical research to establish a theoretical framework based on literature review and by observing the specific practices of enterprises. At the same time, some new dimensions of Chinese situation are added to better reflect the reality of Chinese enterprises, and to construct a theoretical model of successful brand extension, which is shown in Figure 2.

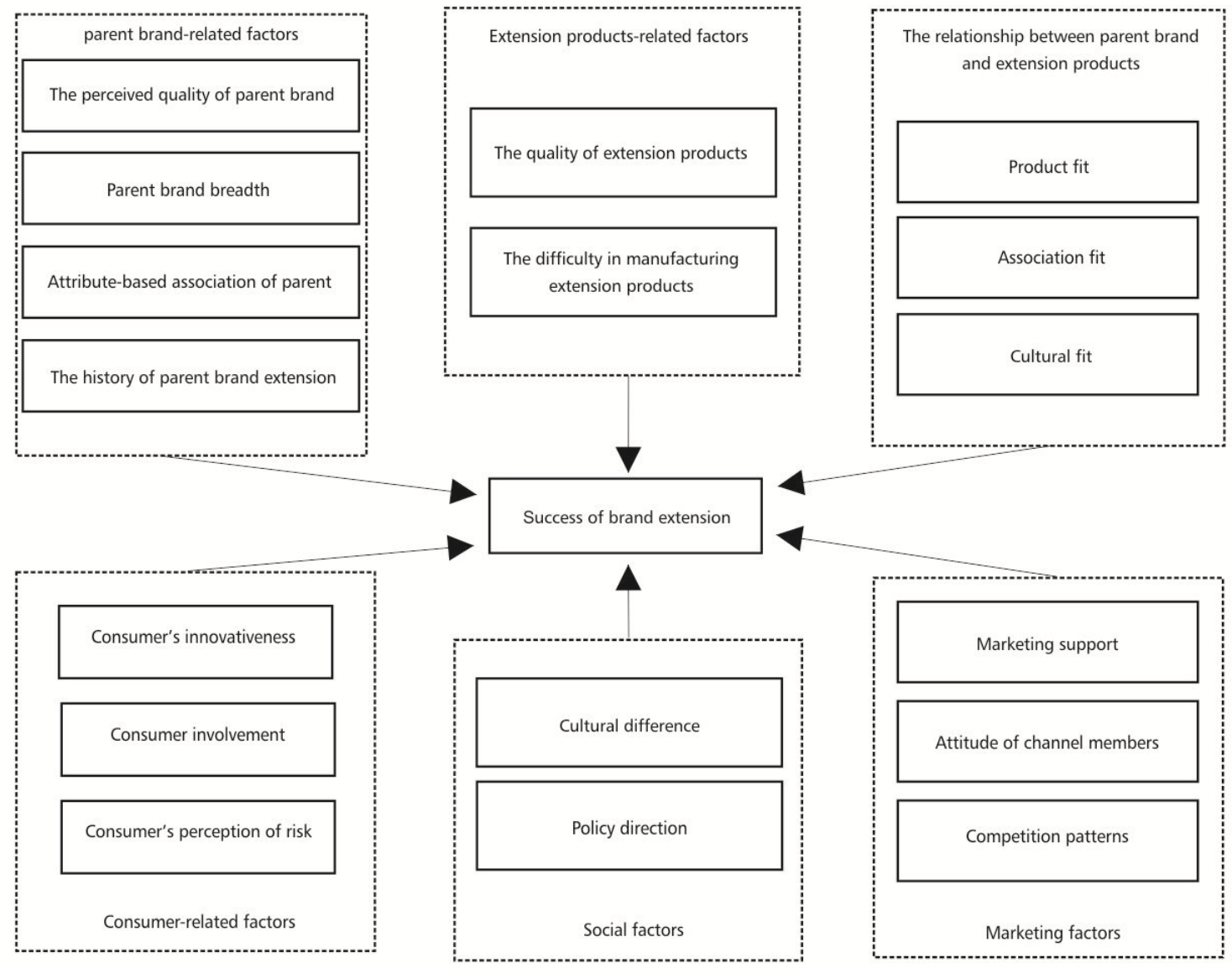

Fig. 2 a model for successful brand extension

\section{Conclusion and reflections}

Through the overview of the researches on brand extension, it can be seen that although the research in this field has only developed for more than 30 years, there are a large number of studies with wide research scope on brand extension abroad. Scholars have studied the value, the opportunity, the effect, the test criteria, the feedback effect and effect measurement of brand 
extension, etc. There are many foreign and Chinese studies on the factors affecting brand extension, but they have difference in the emphasis and methodologies. The criterion for successful brand extension is whether new products are finally recognized by consumers (target market customers). Western scholars mainly focus on brand extension evaluation and what factors affect consumers' attitude towards brand extension; however, they made their research from different perspectives.

As for the factors affecting brand extension, most of the studies in China draw lessons from other countries, focusing on the factors such as parent brand equity (parent brand strength), the correlation between parent brand and extension products, internal and external environmental factors, etc. besides, the scholars elaborated on the key factors affecting brand extension from a qualitative point of view. However, according to the Chinese and western studies on factors affecting brand extension and the existing literature, there are still some areas in this filed which need to be further explored.

Firstly, the researches on brand extension are mainly carried out in the Western cultural context. Therefore, whether the research conclusions can be popularized in the Chinese context is drawing attention of relevant scholars. Up to now, there are just a few studies on brand extension based on local brands in China, so the theoretical research on how to guide Chinese enterprises to carry out the practice of brand extension needs to be further explored. Studying Chinese market and revealing the logic of brand extension's impact on brand image in Chinese market can provide specific theoretical guidance for Chinese brands to effectively implement brand extension. Even though validating the widely accepted conclusions under the framework of Western research in the Chinese cultural context may bring some new problems, such work is still very valuable.

Secondly, nowadays, with the improvement of technology and the development of society, the factors affecting brand extension also change. Besides, the affecting factors of brand extension in different industries vary from each other. Therefore, corresponding affecting factors of extension products in a specific industry should be sorted out to improve the feasibility and scientific nature of relevant researches and to improve their applicability in different industries. Especially, Chinese enterprises are obviously influenced by cultural, policy and social hot issues, and these factors should be timely added to the studies on affecting factors of brand extension. Since Chinese enterprises are much influenced by cultural, policy and social hot issues, these affecting factors also should be added to the studies on factors affecting brand extension.

Thirdly, in terms of research methods, the studies on Chinese brand extension mainly focus on qualitative description and analysis while lacks empirical research results, which leads to the fact that most of the research results are not convincing and can not guide practice. Therefore, the research of brand extension in China should pay attention to quantitative analysis, clarify the antecedent and outcome variables of brand extension through empirical research, and guide enterprises to implement brand extension strategy in a scientific way.

Fourthly, compared with foreign brand extension studies, the samples selected by Chinese scholars are not representative. In order to facilitate their survey, most Chinese empirical studies on brand extension choose college students as research samples. However, college students can only represent a part of the youth consumer group and there are great differences in consumption mentality and behaviors between young consumers and other consumers. As a result, Chinese researchers need to expand the scope of the study and test the applicability of brand extension theory through empirical research.

\section{References}

[1] Aaker D.A., Should You Take Your Brand to Where the Action Is, Harvard Business Review, 9(97), 1997.

[2] Aaker David A, Keller Kevin Lane, Consumer Evaluations of Brand Extensions, Journal of Marketing,23(1), pp.27-28,1990.

[3] Aaker. D.A., managing brand equity, New York: The Free Press. 
[4] BhatsReddysk, Symbolic and Functional Positioning of Brands, Journal of Consumer Marketing,15(1), pp. 32-40,1998.

[5] Boush D M, Shipp S, Loken B, Affect generalization to similar and dissimilar brand extensions, Psychology and Marketing, 12(3), pp.255 -237,1998.

[6] Broniarczyk, Susan M, Alba, J.W., The Importance of the Brand in Brand Extension, Journal of Marketing research, 31 (2), pp.214-229,1994.

[7] Chris Pullig, Carolyn J. Simmons, Richard G. Netemeyer, Brand Dilution: When Do New Brands Hurt Existing Brands? The Journal of Marketing, 2(70), pp. 52-66, 2006.

[8] Diamantopoulos A, Smith Z, Grim e I., The impact of brand extensions on brand personality: experimental evidence European, Journal of Marketing, 39(1/2), pp.129- 149, 2005.

[9] Keller K.L., Aaker D.A, The Effect of Sequential Introduction of Brand Extensions, Journal of Marketing Research, 29(2), pp.134-156.,1992.

[10] Meyvis T, Janiszewski C, When are broader brands stronger brands? An accessibility perspective on the success of brand extensions, Journal of Consumer Research,31(2), pp.346-357, 2004.

[11] Pullig C., Simmons C.J., Netemeyer R. G., Brand Dilution: When Do New Brands Hurt Existing Brands? Journal of Marketing, 70 (2), pp.52-66, 2006.

[12] Sood S., Keller K. L, The Effects of Brand Name Structure on Brand Extension Evaluations and Parent Brand Dilution, Journal of Marketing Research, 49(3), pp.373-382, 2012.

[13] Subodh Bhat, Srinivas K. Reddy, Symbolic and Functional Positioning of Brands, Journal of Consumer Marketing, 1(15), pp.32-43, 1998.

[14] Tauber Edward M, Brand Leverage: Strategy for Growth in a Cost-Controlled World. Journal of Advertising Research, 28, pp.26-30,2005. 